fournal of Medical Genetics (1976). 13, 514-515.

\section{Atypical serum cholinesterase in a family with congenital distichiasis*}

\begin{abstract}
Summary. This paper describes the coexistence of genetically determined reduced cholinesterase activity and congenital distichiasis in the same family. The pedigree suggests that these two autosomal dominant diseases are segregated independently and do not show evidence of linkage.
\end{abstract}

Several genetically determined variants of human serum cholinesterase have been identified (Kalow, 1959; Lehmann and Liddel, 1969; Whittaker, 1970). Individuals homozygous for the so-called 'atypical' allele show relatively low levels of enzyme activity and are excessively sensitive to succinylcholine. They are likely to suffer prolonged apnoea when this drug is used during routine anaesthetic procedures (Evans et al, 1952; Bush, 1961; Baraka et al, 1974). Such cases are relatively uncommon in most populations.

Congenital distichiasis or the presence of two rows of eye-lashes at the lid margins is a rare entity that follows the autosomal dominant mode of inheritance (Falls and Kertesz, 1964; Robinow et al, 1970; Hoover and Kelley, 1971).

The purpose of the present report is to describe the coexistence of distichiasis and atypical cholinesterase in the same family.

\section{Subjects and methods}

A 7-year-old boy (II.9) (see pedigree, Fig. 1) was found to have at the inner edge of each lid margin aberrant eyelashes that were rubbing over the cornea (Fig. 2). During the surgical correction of the distichiasis under general anaesthesia, small doses of succinylcholine $(0.1 \mathrm{mg} / \mathrm{kg})$ injected intravenously produced an abnormally prolonged neuromuscular block.

Received 8 September 1975.

* Supported by Grant No. 38-5757 from the Lebanese National Council for Scientific Research, Beirut, Lebanon.
The serum cholinesterase dibucaine numbers (DN) of the patient and the other members of the family were determined according to the method described by Kalow and Genest (1957). All the members of the family were also examined for the presence of distichiasis.

Finally, all members were tested for the ABO, MNS, $P, R h, L^{a}$, Le, Fy, $j K$, and $X_{g}^{a}$ blood groups.

\section{Results}

The mother and 4 other members of the family (II.2, II.5, II.9, II.13) were found to have distichiasis (Fig. 1).

The results of the dibucaine numbers are shown on the pedigree (Fig. 1). According to these results, the members of the family showed a trimodal distribution. Enzyme activity was found to be low

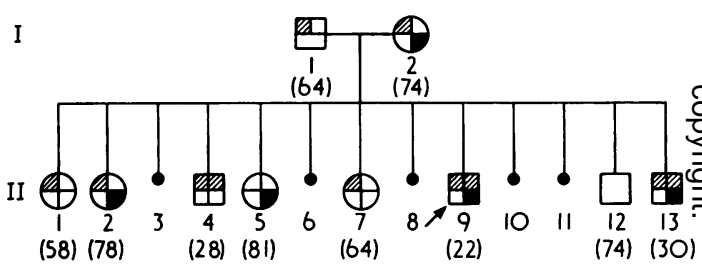

Congenital distichiasis Heterozygous for variont Dibucaine numbers (.....)

Fig. 1.

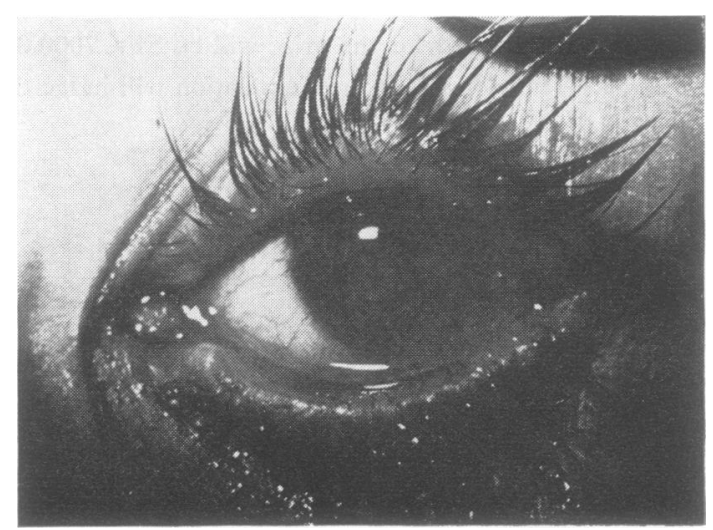

FIG. 2. 
in II.4, II.9, and II.13, normal in II.5 and II.12, and intermediate in I.1, I.2, II.1, II.2, and II.7.

\section{Discussion}

Falls and Kertesz (1964) described a syndrome inherited as autosomal dominant and consisting of different congenital anomalies, mainly distichiasis involving all four lids, chronic lymphatic oedema of the lower extremities appearing at puberty (Milroy's disease), pterygium colli or webbing of the neck, and partial lateral ectropion of both lower lids. Other congenital anomalies such as vertebral anomalies, extradural cysts, and astigmatism were associated later to the syndrome (Chynn, 1967; Bergland, 1968; Robinow et al, 1970; Hoover and Kelley, 1971).

To our knowledge, this is the first published instance of congenital distichiasis and serum cholinesterase deficiency occurring in the same family and the same individuals (II.9 and II.13). The pedigree suggests, however, that these two traits are segregated independently and do not show evidence of linkage. Moreover, the analysis of the blood subgroups did not reveal any linkage either to the gene of distichiasis or to that of pseudocholinesterase.

Hanna F. Shammas, Khalid F. Tabbara, and Vazken M. Der Kaloustian†

From the Department of Ophthalmology and the Department of Pediatrics, American University of Beirut, School of Medicine, Beirut, Lebanon
REFERENCES

Baraka, A., Bikhazi, G., and Abu-Haidar, G. (1974). Succinylcholine block in a patient with atypical serum cholinesterase. Middle East Fournal of Anaesthesia, 4, 53-59.

Bergland, R. M. (1968). Congenital intraspinal extradural cyst: report of three cases in one family. Fournal of Neurosurgery, 28, 495-499.

Bush, G. (1961). Prolonged apnoea due to suxamethonium. British fournal of Anaesthesia, 33, 454-462.

Chynn, K. Y. (1967). Congenital spinal extradural cyst in two siblings. American fournal of Roentgenology, 101, 204-215.

Evans, F. T., Gray, P. W. S., Lehmann, H., and Silk, E. (1952). Sensitivity to succinylcholine in relation to serum cholinesterase. Lancet, 1, 1229-1230.

Falls, H. F. and Kertesz, E. D. (1964). A new syndrome combining pterygium colli with developmental anomalies of the eyelids and lymphatics of the lower extremities. Transactions of the American Ophthalmological Society, 62, 248-275.

Hoover, R. E. and Kelley, J. S. (1971). Distichiasis and lymphedema, a hereditary syndrome with possible multiple defects. A report of a family. Transactions of the American Ophthalmological Society, 69, 293-306.

Kalow, W. (1959). The distribution, destruction and elimination of muscle relaxants. Anesthesiology, 20, 505-518.

Kalow, W. and Genest, K. (1957). A method for the detection of atypical forms of human serum cholinesterase. Determination of dibucaine numbers. Canadian fournal of Biochemistry, 35, 339342.

Lehmann, H. and Liddel, J. (1969). Human cholinesterase (pseudocholinesterase). Genetic variants and their recognition. British Fournal of Anaesthesia, 41, 235-244.

Robinow, M., Johnson, G. F., and Verhagen, A. D. (1970). Distichiasis-lymphedema. American fournal of Diseases of Childhood, 119, 343-347.

Whittaker, M. (1970). Genetic aspects of succinylcholine sensitivity. Anaesthesia, 32, 143-150.

† Reprint requests to Dr Vazken M. Der Kaloustian, Biochemical Genetics, Montreal Children's Hospital, 2300 Tupper St., Montreal, Quebec,Canada. 